\title{
RNA Interference, Heterochromatin, and Centromere Function
}

\author{
R.C. ALLSHIRE \\ Wellcome Trust Centre for Cell Biology, University of Edinburgh, The King's Buildings, Edinburgh \\ EH9 3JR, Scotland, United Kingdom
}

The centromere regions of most eukaryotic metaphase chromosomes are distinctive. The narrower, more compact appearance of these regions reflects two important related features: centromeric cohesion and extensive blocks of heterochromatin. First, sister centromeres remain associated because the cohesin complex remains intact at centromeres until anaphase. Second, the chromatin coating these regions is very different since they remain condensed throughout the cell cycle and are clearly visible as the most concentrated foci of DNA in interphase cells; this has been termed heterochromatin (Bernard and Allshire 2002).

It has been known for many years that marker genes placed close to or within such centromeric heterochromatin regions are transcriptionally silenced, often resulting in a variegated phenotype (PEV) reflecting variability in the ability to silence marker genes. Genetic analyses in Drosophila allowed the identification of two important conserved proteins involved in the assembly of this silent heterochromatin. The original mutants were termed $\mathrm{Su}$ (var) (suppressor of variegation): The su(var)3-9 and su(var)2-5 genes were found to encode Suv39 (histone H3 lysine 9 methyl transferase) and HP1 (Heterochromatin protein 1), respectively (Reuter and Spierer 1992; Dillon and Festenstein 2002; Richards and Elgin 2002; Schotta et al. 2003). Both Suv39 and HP1 proteins associate with each other and are concentrated in the large blocks of heterochromatin in pericentromeric regions in both fly and mammalian cells (James et al. 1989; Wreggett et al. 1994; Aagaard et al. 1999; Minc et al. 1999).

Fission yeast centromere regions bear some resemblance to the large repetitive structures found at fly, plant, and mammalian centromeres (Takahashi et al. 1992; Steiner et al. 1993). Large inverted repetitive structures surround a central core domain (Fig. 1). The central region and the inner repeats have a relatively high $\mathrm{A}+\mathrm{T}$ content and are packaged in unusual chromatin that generates a diffuse smear, rather than a canonical ladder pattern, upon limited digestion with micrococcal nuclease (Polizzi and Clarke 1991; Takahashi et al. 1992). This probably reflects the fact that most $\mathrm{H} 3$ is replaced by the conserved kinetochore specific histone H3-like protein CENP-A ${ }^{\mathrm{cnp} 1}$ in this central domain (B. Mellone and R.C. Allshire, unpubl.). The outer repeats are coated in nucleosomes which are generally underacetylated on lysines in the amino-terminal tails of histones H3 and H4. This hy- poacetylated state is important for centromere integrity and function (Ekwall et al. 1997).

The formation of a functional centromere and kinetochore assembly requires at least one outer repeat and a central core region (Takahashi et al. 1992; Marschall and Clarke 1995; Ngan and Clarke 1997). The central core alone is unable to be packaged in unusual chromatin when replicated on an extrachromosomal plasmid or other sites in the genome or when replicated in Saccharomyces cerevisiae (Polizzi and Clarke 1991; Takahashi et al. 1992). Thus, this "unusual" CENP-A chromatin is not specified by the underlying DNA sequence within this region alone, but it must be induced by the context in which these sequences are placed. The outer repeats must provide this contextual specificity (Fig. 1).

\section{VARIABLE ESTABLISHMENT OF FUNCTIONAL CENTROMERES}

It is apparent that epigenetic processes act to govern the assembly of a functional centromere in fission yeast. First, erasing the hypoacetylated state of the outer repeats by transiently blocking histone deacetylation (and presumably histone $\mathrm{H} 3$ lysine 9 methylation) generates a defective, hypoacetylated centromere state that can be propagated through several divisions and meiosis (Ekwall et al. 1997). Second, truncated centromeres on episomal plasmids in the fission yeast nucleus can provide centromere function resulting in reasonable mitotic segregation (Takahashi et al. 1992; Baum et al. 1994). However, the introduction of minimal constructs with part of an outer repeat plus a central domain frequently appear nonfunctional. Nevertheless, in a variable proportion of these transformants functional centromeres are established, imparting mitotic stability on the episome (Steiner and Clarke 1994; Ngan and Clarke 1997). Once established this functional state is propagated through mitotic and meiotic divisions. It seems likely that these minimal constructs struggle to set up the contextual information required to trigger CENP-A and kinetochore assembly over the adjacent central domain; however, this has not been directly assessed. Consistent with this, only constructs that establish the functional state display "unusual" central core/kinetochore chromatin, but it is not known how this correlates with CENP-A incorporation (Marschall and Clarke 1995). Even so, the removal of outer repeat hete- 


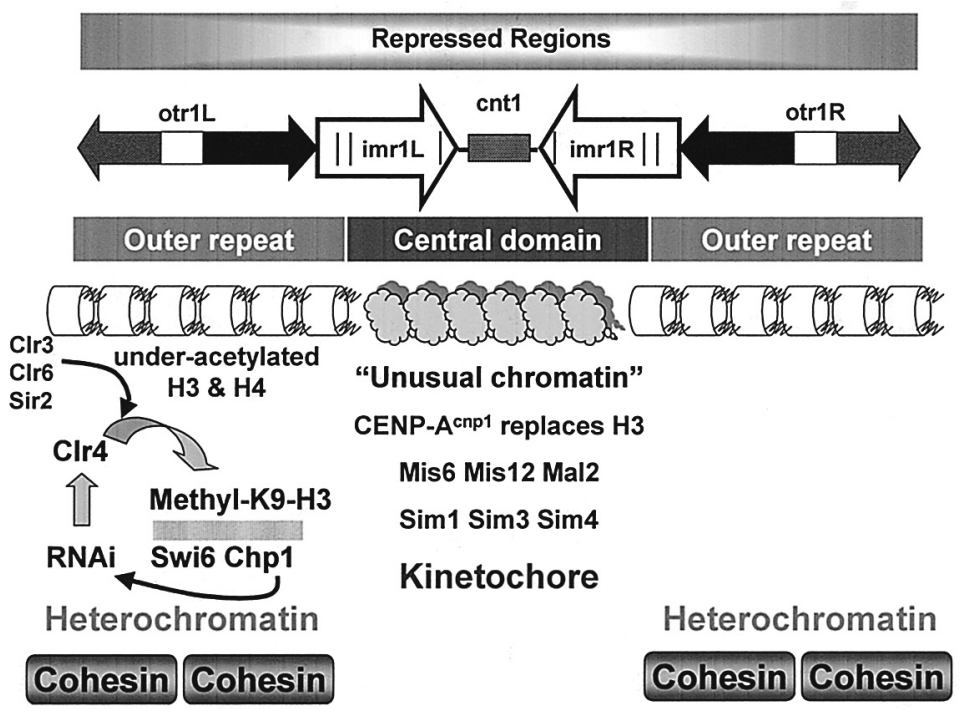

Figure 1. Schematic diagram of fission yeast centromere 1. Outer repeats (otr1) along with innermost repeats (imr1) form a long, almost perfect 18-kb inverted repeat around the central core (Cnt1). Vertical lines represent tRNA genes. The imr and cnt1 make up the central domain. Insertion of the ura 4 gene anywhere within the outer repeats or central domain results in its transcriptional repression. Different factors are required to mediate silencing within the central domain and the outer repeats. An "unusual" chromatin structure is associated with the central domain where $\mathrm{H} 3$ is replaced by the kinetochore-specific histone H3-like protein CENP-A. Mutations of the gene encoding CENP-A ${ }^{\text {cnp1 }}$ (sim2), Sim1, Sim3, Sim4, Mis6, Mis12, or Mal2 all specifically affect central core silencing. CENP-A, Sim4, Mis6, Mis12, and Mal2 are kinetochore-specific proteins and only associate with the central domain. Where examined, most mutants that affect kinetochore function disrupt the "unusual" central core chromatin structure. Nucleosomes with hypoacetylated amino-terminal tails on $\mathrm{H} 3$ and $\mathrm{H} 4$ coat the outer repeats, thus the action of HDACs allows dimethylation of lysine 9 on $\mathrm{H} 3$ by the histone methyltransferase Clr4 and binding of Swi6 and Chp1 via their chromodomains. This results in the recruitment of a high density of cohesin over the outer repeats and this mediates sister centromere cohesion counteracting the pulling forces upon bilateral spindle attachment. The RNAi components Ago1, Dcr1, Rdp1, and Tas3 are required to process outer repeat transcripts and bring about methylation of histone $\mathrm{H} 3$ on lysine 9. Chpl is also required for methylation of lysine $9 \mathrm{H} 3$. Methylation of lysine 9 still occurs in the absence of Swib.

rochromatin from established functional centromeres (e.g., by deletion of RNAi components, clr4+, or swi6+) leaves centromeres that retain a reasonably functional kinetochore. In contrast, DNA constructs lacking outer repeat DNA are unable to establish the functional state. This implies that the heterochromatic outer repeats are required to provide a favorable environment for kinetochore assembly but that once established the kinetochore no longer requires flanking heterochromatin for its propagation.

\section{PROPAGATION OF THE FUNCTIONAL CENTROMERE STATE}

Because CENP-A chromatin must be pivotal in inducing kinetochore assembly over the central region, there must be specific factors that ensure that CENP-A is only assembled into chromatin in this central region and not elsewhere on chromosomes. Mutations in several kinetochore factors affect the "unusual" kinetochore specific chromatin structure and CENP-A accumulation at centromeres (Fig. 1) (Saitoh et al. 1997; Goshima et al. 1999; Takahashi et al. 2000; Jin et al. 2002; Pidoux et al. 2003). Analyses in other organisms indicate that sites of kinetochore assembly are plastic and epigentically regulated (Karpen and Allshire 1997; Sullivan et al. 2001). Why might this be? It is well known that there must be one and only one centromere per chromosome: Dicentric chromosomes are unstable and this genome instability leads to loss of genetic information. Consequently it would seem sensible to have the process of active centromere duplication and propagation coupled in some manner to the machinery that habitually senses the formation of functional kinetochores. It is well documented that eukaryotes possess a metaphase-anaphase checkpoint that operates by sensing microtubule attachment and thus tension generated between sister centromeres upon capturing microtubules rooted in opposite poles (Millband et al. 2002; Musacchio and Hardwick 2002).

An attractive idea is that the tension and associated conformational changes generated by correct biorientation of sister kinetochores and progression into anaphase induces a "mark" that is subsequently interpreted to allow CENPA incorporation (Fig. 2) (Mellone and Allshire 2003). This mark could be read by either a replication-coupled or a replication-independent mechanism of CENP-A deposition and chromatin assembly. Such a device would allow fully active functional centromeres to be propagated at the same site through multiple cell divisions whereas defective centromeres might wither after several divisions. In addition, if the correct circumstances contrive to generate a favorable context elsewhere on a chromosome, CENPA incorporation might allow the establishment of a new site of kinetochore assembly - a neocentromere (Karpen and Allshire 1997; Sullivan et al. 2001; Amor and Choo 2002) — which, if it biorients on a regular basis, will be propagated through multiple divisions. 


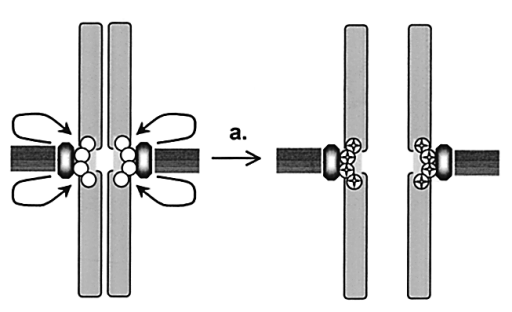

Functional Centromere

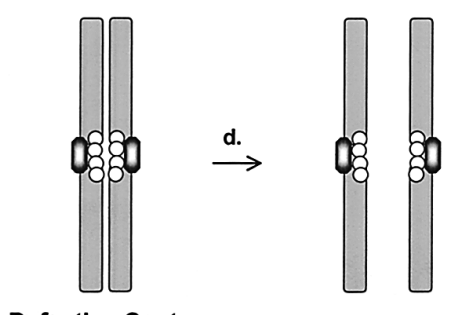

Defective Centromere

Figure 2. Model for the propagation and loss of a site of centromere activity. Active centromeres allow the assembly of sister kinetochores that capture microtubules emanating from opposite spindle poles during mitosis, resulting in biorientation, chromatin stretching, and the generation of tension between sister kinetochores. Microtubule attachment and tension are recognized as signals for progression into anaphase $(a)$ when sister chromatids separate. We propose that the resulting tension of a correctly bioriented kinetochore also marks the underlying active kinetochore chromatin in some manner (directly or indirectly) (४) so that perhaps during the next $\mathrm{S}$ phase this mark is recognized at the replication fork and ensures that CENP-A nucleosomes rather than $\mathrm{H} 3$ nucleosomes are assembled in its wake $(b)$. Completion of $\mathrm{S}$ phase results in two sister centromeres with a full complement of CENP-A and thus a robust kinetochore $(c)$. Alternatively, replication-independent assembly mechanisms may recognize the marked CENP-A chromatin and strip out any potentially hindering $\mathrm{H} 3$, replacing it with CENP-A after replication is completed. If a centromere fails to biorient, no tension is generated so that the mark is not placed at the centromere at metaphase/anaphase. Thus in the following $\mathrm{S}$ phase (e), there is no signal to direct CENP-A chromatin assembly and therefore normal $\mathrm{H} 3$-containing nucleosomes are incorporated and remain at this defective centromere ( $f$ ). If this centromere fails again to biorient it will again lose more CENP$\mathrm{A}$, and thus it will be more likely to lose function completely.

\section{OUTER REPEAT HETEROCHROMATIN}

The outer repeats of fission yeast centromeres resemble to some extent the arrays of repeats associated with metazoan centromere regions. Because no steady-state transcripts could be detected, it was suggested that they may be heterochromatic (Fishel et al. 1988). It has also been noted that these tandem outer repeats resemble transposable elements (Halverson et al. 1997). Mobile elements of various types are associated with centromere regions of many species and may contribute to the heterochromatic nature of these regions. The high density of various repeats can be detected as heterochromatin coincident with the large foci of DAPI staining in interphase nuclei. In general, genes that become embedded in this heterochromatin are transcriptionally silenced (Reuter and Spierer 1992; Dillon and Festenstein 2002; Richards and Elgin 2002; Schotta et al. 2003). The insertion of the $\mathrm{urat}^{+}$ marker gene at any site within the centromeric outer repeats, inner repeats, or central core results in repression of its transcription (Allshire et al. 1994, 1995). The quality of silencing associated with the central region (imr + central core) and outer repeats differs and presumably reflects the distinctly different chromatin associated with these regions. Silencing within the central kinetochore region is unstable so that expressing and nonexpressing colonies are generated at high frequencies. Marker genes with compromised promoters allow more robust phenotypic silencing when inserted in the central core. This has allowed genetic screens for factors affecting repression within the central domain (Pidoux et al. 2003). Such screens have identified CENP-A itself, novel kinetochore proteins, and other proteins that are required for the association of normal levels of CENP-A with the central region (Fig. 1).

In contrast, silencing of markers placed in the outer repeats is much tighter with very few expressing colonies detected. The outer repeats are packaged in hypoacetylated nucleosomes (Ekwall et al. 1997). This state is mediated by the action of three histone deacetylases, Clr3, Clr6, and Sir2 (Nakayama et al. 2001; Bjerling et al. 2002; Shankaranarayana et al. 2003). Clr3 activity is mainly directed toward deacetylation of histone $\mathrm{H} 3$ on lysine 14; Clr6 has a more broad affect on deacetylation of several lysine residues in $\mathrm{H} 3$ and $\mathrm{H} 4$; and $\mathrm{Sir} 2$ participates in deacetylating lysine 9 in the process of spreading the assembly of this silent chromatin outward from a nucleation site along the chromatin fiber.

The action of these histone deacetylases paves the way for the activity of the histone methyltransferase $\mathrm{Clr} 4$ (orthologous to Suv39) (Rea et al. 2000). Clr4 methylates histone $\mathrm{H} 3$ on lysine 9 forming a binding site for the key heterochromatin protein Swi6 (counterpart of HP1) to form transcriptionally repressive chromatin at centromeres (Allshire et al. 1995; Bannister et al. 2001; Lachner et al. 2001; Nakayama et al. 2001).

Small fragments $(\sim 1 \mathrm{~kb})$ taken from the centromeric outer repeats can mediate silent chromatin formation when placed at an ectopic euchromatic locus (Partridge et al. 2002). What directs this silent chromatin assembly? Such experiments might suggest that DNA sequence specific binding proteins simply directly recruit chromatin modifying and remodeling complexes that mediate heterochromatin formation. However, the astonishing finding that the RNA interference pathway is required for the formation of this outer repeat heterochromatin made a seminal link between heterochromatin and RNAi that is likely conserved (Fig. 1) (Volpe et al. 2002).

Deletion of genes encoding three components of the RNAi pathway, Argonaute (Ago1), Dicer (Dcr1), or RNA-dependent RNA polymerase (Rdp1), leads to loss of methylation of histone $\mathrm{H} 3$ on lysine 9 of, and Swi6 binding to, outer repeat chromatin coupled with alleviation of marker gene silencing within this centromeric heterochromatin but not in the central domain occupied by the kinetochore (Volpe et al. 2002). Noncoding transcripts of specific sizes from the outer repeats can be detected in these cells that lack active RNAi but not in wildtype cells. Transcripts from top and bottom outer repeat 
strands, which overlap in sequence, are produced. Thus this potentially allows the formation of double-stranded RNA, which then serves as a substrate for Dicer and the generation of homologous siRNAs (Reinhart and Bartel 2002; Volpe et al. 2002). The incorporation of these siRNAs into a RNA-induced silencing complex (RISC)like complex (e.g., RNA-induced initiation of transcriptional gene silencing [RITS]) allows homologous loci to be targeted and degraded (Verdel et al. 2004).

The chromodomain protein Chp1 is required for methylation of histone $\mathrm{H} 3$ on lysine 9 , binds dimethylated lysine $9 \mathrm{H} 3$ peptide in vitro, and is dependent on the activity of the Clr4 lysine 9 H3 HMTase for recruitment to outer repeats in vivo (Partridge et al. 2002). Chp1 has been shown to interact with Ago1 in the RITS complex making a link between the RNAi machinery and silent chromatin (see Fig. 1) (Verdel et al. 2004).

\section{HOW DO SIRNAS EFFECT CHROMATIN MODIFICATION ON HOMOLOGOUS DNA?}

Our view is that siRNAs act on nascent transcripts and that the chromatin modifying activities, a lysine 9 histone H3 deacetylase (Clr3/Clr6) and histone methyltransferase (Clr4), piggyback on the RNAi machinery to modify the juxtaposed chromatin (Fig. 3). An alternative model is suggested by experiments in plants that demonstrated that

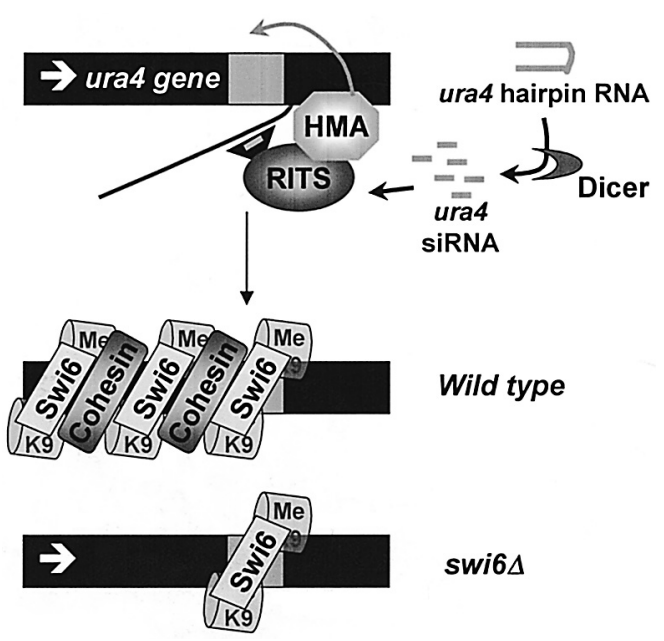

Figure 3. Hairpin RNAs induce heterochromatin assembly on a euchromatic gene. Expression of a 280-bp region as an inverted hairpin, homologous to a central portion of the $\mathrm{ura}^{+}$gene, results in transcriptional silencing of the normally euchromatic $\mathrm{ura}^{+}$gene. The resulting siRNAs generated by the action of Dicer are taken up by a RISC-like complex (e.g., RITS) and home in on homologous nascent ura4 transcripts at the $\mathrm{ura}^{+}{ }^{+}$locus in the nucleus. Association with nascent transcripts allows the recruitment of histone-modifying activities (HMAs: HDACs and Clr4 HMTase) that mediate methylation of histone $\mathrm{H} 3$ in the vicinity, allowing recruitment of Swi6 and even Rad21-cohesin. This silent chromatin spreads approximately $750 \mathrm{bp}$ into the $\mathrm{ura}^{+}$promoter in wild-type cells. In cells lacking Swi6, methylation is still detected over the region of $\mathrm{ura}^{+}$homologous to the 280-bp hairpin but it no longer spreads to the promoter. This is consistent with Swi6 binding allowing further $\mathrm{Clr} 4$ recruitment so that silent chromatin extends along the chromatin fiber from the nucleation site (Shankaranarayana et al. 2003).

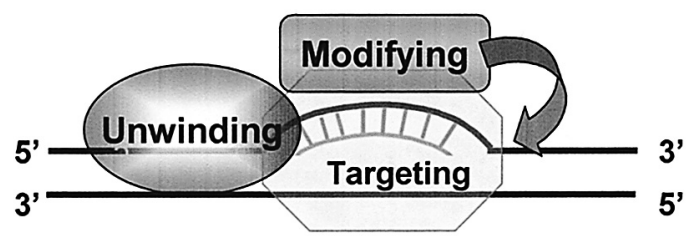

Figure 4. siRNA-DNA interactions in chromatin modification and silencing. The hybridization of siRNA with homologous DNA may induce the recruitment of DNA/chromatin-modifying activities that promote silent chromatin assembly. siRNA may gain access passively during replication or alternatively DNA unwinding activities may act in a complex with siRNAs to unwind DNA and allow access.

siRNAs homologous to a transgene promoter can also bring about RNA-dependent target modification and robust silencing (Fig. 4). Because it is expected that the promoter itself is not transcribed, the prevailing view is that siRNA-DNA interactions could mediate silencing of these transgenes (Jones et al. 1999; Mette et al. 2000).

However, our analyses in fission yeast suggest that transcription of the homologous target sequences is required (R.C. Allshire and V. Schramke, unpubl.). This suggests that siRNA may home in on nascent transcripts and in so doing recruit various histone-modifying activities (HMAs: HDACs and HMTase) that mediate histone modification and heterochromatin assembly. This is somewhat analogous to the association of other histonemodifying activities with elongating RNA polymerase II; for example, the SET1 and SET2 H3 lysine 4 and lysine 36 HMT' $^{\prime}$ ases are recruited via the CTD of RNApolII (Hampsey and Reinberg 2003). It thus seems plausible that siRNAs and associated proteins may also allow the recruitment of histone deacetylases and Clr4 histone metyltranferase to a homologous nascent transcript in the act of being produced by elongating RNA polymerase.

\section{RETROTRANSPOSONS SHOW A SIMILAR REGULATION TO CENTROMERE REPEATS}

If the repetitive regions associated with centromeres are indeed derived from centromeres, one might expect that retrotransposons and remnant, solo long terminal repeats (LTRs) may also be assembled in RNAi-dependent heterochromatin. Our analyses demonstrated that fission yeast TF1 and TF2 solo LTRs are packaged in chromatin that is methylated on lysine 9 of histone $\mathrm{H} 3$ and, just like at centromeres, this heterochromatin is lost when ggol $^{+}$, $d c r 1^{+}$, or $r d p 1^{+}$are deleted, resulting in the detection of transcripts homologous to both template strands (Schramke and Allshire 2003). Further analyses indicated that the repression of nearby genes is enforced by these LTRs.

This raises the possibility that the generation of double-stranded RNA alone is sufficient to bring about the assembly of heterochromatin on homologous DNA. To test this we expressed a hairpin RNA homologous to the middle of the $\mathrm{ura}^{+}$transcription unit (Fig. 3). This resulted in loss of $\mathrm{ura}^{+}$transcripts, methylation of the $\mathrm{ura}^{+}$gene, recruitment of Swi6, and Rad21 cohesin 
(Schramke and Allshire 2003). Therefore, it appears that no specific DNA sequence is required for the assembly of heterochromatin. Thus silent chromatin assembly may be inextricably linked to the generation of homologous double-stranded RNA and may form part of an endogenous surveillance mechanism that acts to clear such aberrant dsRNAs from the cell.

\section{WHAT IS THE ROLE OF HETEROCHROMATIN AT CENTROMERES?}

Heterochromatin regions are known to be "sticky" and sister chromatids remain associated in heterochromatic regions (Bernard and Allshire 2002). In the absence of RNAi, Clr4, or Swi6, cells display elevated rates of chromosome loss and a specific defect in mitosis, lagging chromosomes on late anaphase spindles (Ekwall et al. 1995; 1996; Hall et al. 2003; Volpe et al. 2003). It is now clear that mutants that lack Swi6 at centromeres also display a defect in cohesion at centromeres but not along chromosome arms (Bernard et al. 2001; Nonaka et al. 2002). Thus, centromeric Swi6 heterochromatin is required to mediate strong physical cohesion between sister centromeres and thereby ensure normal chromosome segregation. The defect in segregation must be due to aberrant kinetochore-spindle microtubule interactions. One possibility is that centromeres lacking heterochromatin are disorganized so that the multiple microtubule (MT) binding sites at a stable kinetochore are not rigidly oriented toward one pole but can connect with MTs rooted in opposite poles. This configuration is known as merotelic orientation and is very prevalent in somatic vertebrate cells $(\mathrm{Ci}-$ mini et al. 2001). We propose that the heterochromatin that flanks the kinetochore is required to present the kinetochore in a rigid structure so that the multiple MT bind-

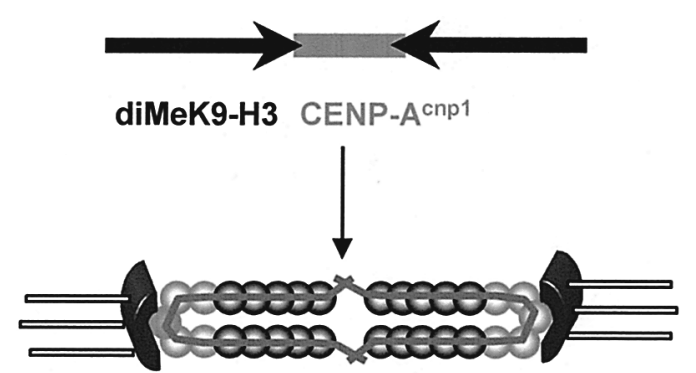

Figure 5. A structural role for heterochromain at centromeres. RNAi, Clr4, Swi6, and cohesin mutants all display a high frequency of lagging chromosomes on late anaphase spindles. Centromeres in metazoans are known to be modular and other observations indicate that stretches of CENP-A and H3 chromatin are intermingled along the chromatin fiber. This has prompted the suggestion that these fibers are coiled or looped to present the CENP-A chromatin on the outer surface of the chromosome so that it induces kinetochore assembly on opposite sides ensuring that sisters interact with microtubules rooted in opposite poles (Sullivan et al. 2001). The left and right sides of fission yeast centromeres may fold on each other, forming a superstructure that holds the central CENP-A domains in a rigid back-to-back orientation to promote biorientation (see Fishel et al. 1988; Takahashi et al. 1992). Loss of heterochromatin disrupts this superstructure, allowing perhaps merotelic orientation of single kinetochores and thus lagging chromosomes during late anaphase. ing sites all face the same direction and only connect with MTs emanating from the same pole (Fig. 5).

\section{CONCLUSION}

The fission yeast genome is borne on three chromosomes and fission yeast centromeres are 150 times larger than the best characterized "point" centromeres in budding yeast. The main difference is that fission yeast centromeres are subdivided into kinetochore chromatin and flanking repetitive heterochromatin, an organization that resembles that of regional metazoan centromeres. Surprisingly, budding yeast lacks centromeric heterochromatin, RNAi components, histone $\mathrm{H} 3$ methylated on lysine 9, and a Swi6/HP1 homolog. One of the main differences is that fission yeast centromeres associate with multiple microtubules during mitosis whereas one microtuble contacts each $S$. cerevisiae centromere (Ding et al. 1993; O'Toole et al. 1999). It seems that one role for this heterochromatin is to mediate robust physical cohesion between sister centromeres and thus presumably to counteract the pulling forces created by biorientation. However, this heterochromatin also appears to play an architectural role preventing merotelic association of multiple microtubule binding sites at a single kinetochore from capturing spindle fibers rooted in opposite poles. Another possible role for this heterochromatin is that it may provide a favorable environment for the assembly of kinetochore-specific CENP- $\mathrm{A}^{\text {cnp1 }}$ chromatin leading to kinetochore formation.

The fact that similar RNAi-dependent Swi6-silent chromatin is formed over retrotransposon LTRs and centromere outer repeats suggests that these outer repeats may be derived from ancient mobile elements, which now take on a key role in centromere structure and function. The fact that a synthetic hairpin RNA can also elicit heterochromatin assembly on homologous genes indicates that no "magic" cis acting sequence is necessary for heterochromatin assembly. The siRNAs generated by the double-stranded RNA are sufficient to trigger the required chromatin modification events at the homologous locus.

\section{ACKNOWLEDGMENTS}

R.C.A. thanks past and present members of the lab for discussions and input, especially Alison Pidoux and Vera Schramke. Thanks also to Elaine Dunleavy and Sharon White for reading and making comments on the manuscript. R.C.A. is a Wellcome Trust Principal Research Fellow.

\section{REFERENCES}

Aagaard L., Laible G., Selenko P., Schmid M., Dorn R., Schotta G., Kuhfittig S., Wolf A., Lebersorger A., Singh P.B., Reuter G., and Jenuwein T. 1999. Functional mammalian homologues of the Drosophila PEV-modifier Su(var)3-9 encode centromere-associated proteins which complex with the heterochromatin component M31. EMBO J. 18: 1923.

Allshire R.C., Javerzat J.P., Redhead N.J., and Cranston G. 1994. Position effect variegation at fission yeast centromeres. Cell 76: 157 . 
Allshire R.C., Nimmo E.R., Ekwall K., Javerzat J.P., and Cranston G. 1995. Mutations derepressing silent centromeric domains in fission yeast disrupt chromosome segregation. Genes Dev. 9: 218.

Amor D.J. and Choo K.H. 2002. Neocentromeres: Role in human disease, evolution, and centromere study. Am. J. Hum. Genet. 71: 695 .

Bannister A.J., Zegerman P., Partridge J.F., Miska E.A., Thomas J.O., Allshire R.C., and Kouzarides T. 2001. Selective recognition of methylated lysine 9 on histone H3 by the HP1 chromo domain. Nature 410: 120.

Baum M., Ngan V.K., and Clarke L. 1994. The centromeric Ktype repeat and the central core are together sufficient to establish a functional Schizosaccharomyces pombe centromere. Mol. Biol. Cell 5: 747.

Bernard P. and Allshire R. 2002. Centromeres become unstuck without heterochromatin. Trends Cell Biol. 12: 419.

Bernard P., Maure J.F., Partridge J.F., Genier S., Javerzat J.P., and Allshire R.C. 2001. Requirement of heterochromatin for cohesion at centromeres. Science 294: 2539.

Bjerling P., Silverstein R.A., Thon G., Caudy A., Grewal S., and Ekwall K. 2002. Functional divergence between histone deacetylases in fission yeast by distinct cellular localization and in vivo specificity. Mol. Cell. Biol. 22: 2170.

Cimini D., Howell B., Maddox P., Khodjakov A., Degrassi F., and Salmon E.D. 2001. Merotelic kinetochore orientation is a major mechanism of aneuploidy in mitotic mammalian tissue cells. J. Cell Biol. 153: 517.

Dillon N. and Festenstein R. 2002. Unravelling heterochromatin: Competition between positive and negative factors regulates accessibility. Trends Genet. 18: 252.

Ding R., McDonald K.L., and McIntosh J.R. 1993. Three-dimensional reconstruction and analysis of mitotic spindles from the yeast, Schizosaccharomyces pombe. J. Cell Biol. 120: 141 .

Ekwall K., Olsson T., Turner B.M., Cranston G., and Allshire R.C. 1997. Transient inhibition of histone deacetylation alters the structural and functional imprint at fission yeast centromeres. Cell 91: 1021.

Ekwall K., Javerzat J.P., Lorentz A., Schmidt H., Cranston G., and Allshire R. 1995. The chromodomain protein Swi6: A key component at fission yeast centromeres. Science 269: 1429.

Ekwall K., Nimmo E.R., Javerzat J.P., Borgstrom B., Egel R., Cranston G., and Allshire R. 1996. Mutations in the fission yeast silencing factors clr4+ and rik1+ disrupt the localisation of the chromo domain protein Swi6p and impair centromere function. J. Cell Sci. 109: 2637.

Fishel B., Amstutz H., Baum M., Carbon J., and Clarke L. 1988. Structural organization and functional analysis of centromeric DNA in the fission yeast Schizosaccharomyces pombe. Mol. Cell. Biol. 8: 754.

Goshima G., Saitoh S., and Yanagida M. 1999. Proper metaphase spindle length is determined by centromere proteins Mis 12 and Mis6 required for faithful chromosome segregation. Genes Dev. 13: 1664.

Hall I.M., Noma K., and Grewal S.I. 2003. RNA interference machinery regulates chromosome dynamics during mitosis and meiosis in fission yeast. Proc. Natl. Acad. Sci. 100: 193.

Halverson D., Baum M., Stryker J., Carbon J., and Clarke L. 1997. A centromere DNA-binding protein from fission yeast affects chromosome segregation and has homology to human CENP-B. J. Cell Biol. 136: 487.

Hampsey M. and Reinberg D. 2003. Tails of intrigue: Phosphorylation of RNA polymerase II mediates histone methylation. Cell 113: 429.

James T.C., Eissenberg J.C., Craig C., Dietrich V., Hobson A., and Elgin S.C. 1989. Distribution patterns of HP1, a heterochromatin-associated nonhistone chromosomal protein of Drosophila. Eur. J. Cell Biol. 50: 170.

Jin Q.W., Pidoux A.L., Decker C., Allshire R.C., and Fleig U. 2002. The mal2p protein is an essential component of the fission yeast centromere. Mol. Cell. Biol. 22: 7168.

Jones L., Hamilton A.J., Voinnet O., Thomas C.L., Maule A.J., and Baulcombe D.C. 1999. RNA-DNA interactions and DNA methylation in post-transcriptional gene silencing. Plant Cell 11: 2291.

Karpen G.H. and Allshire R.C. 1997. The case for epigenetic effects on centromere identity and function. Trends Genet. 13: 489.

Lachner M., O'Carroll D., Rea S., Mechtler K., and Jenuwein T. 2001. Methylation of histone H3 lysine 9 creates a binding site for HP1 proteins. Nature 410: 116.

Marschall L.G. and Clarke L. 1995. A novel cis-acting centromeric DNA element affects $S$. pombe centromeric chromatin structure at a distance. J. Cell Biol. 128: 445.

Mellone B.G. and Allshire R.C. 2003. Stretching it: putting the CEN(P-A) in centromere. Curr. Opin. Genet. Dev. 13: 191.

Mette M.F., Aufsatz W., van der Winden J., Matzke M.A., and Matzke A.J. 2000. Transcriptional silencing and promoter methylation triggered by double-stranded RNA. EMBOJ. 19: 5194.

Millband D.N., Campbell L., and Hardwick K.G. 2002. The awesome power of multiple model systems: Interpreting the complex nature of spindle checkpoint signaling. Trends Cell Biol. 12: 205.

Minc E., Allory Y., Worman H.J., Courvalin J.C., and Buendia B. 1999. Localization and phosphorylation of HP1 proteins during the cell cycle in mammalian cells. Chromosoma 108: 220.

Musacchio A. and Hardwick K.G. 2002. The spindle checkpoint: Structural insights into dynamic signalling. Nat. Rev. Mol. Cell Biol. 3: 731 .

Nakayama J., Rice J.C., Strahl B.D., Allis C.D., and Grewal S.I. 2001. Role of histone H3 lysine 9 methylation in epigenetic control of heterochromatin assembly. Science 292: 110.

Ngan V.K. and Clarke L. 1997. The centromere enhancer mediates centromere activation in Schizosaccharomyces pombe. Mol. Cell. Biol. 17: 3305.

Nonaka N., Kitajima T., Yokobayashi S., Xiao G., Yamamoto M., Grewal S.I., and Watanabe Y. 2002. Recruitment of cohesin to heterochromatic regions by Swi6/HP1 in fission yeast. Nat. Cell Biol. 4: 89.

O'Toole E.T., Winey M., and McIntosh J.R. 1999. High-voltage electron tomography of spindle pole bodies and early mitotic spindles in the yeast Saccharomyces cerevisiae. Mol. Biol. Cell 10: 2017.

Partridge J.F., Scott K.S., Bannister A.J., Kouzarides T., and Allshire R.C. 2002. cis-acting DNA from fission yeast centromeres mediates histone $\mathrm{H} 3$ methylation and recruitment of silencing factors and cohesin to an ectopic site. Curr. Biol. 12: 1652.

Pidoux A.L., Richardson W., and Allshire R.C. 2003. Sim4: A novel fission yeast kinetochore protein required for centromeric silencing and chromosome segregation. J. Cell Biol. 161: 295.

Polizzi C. and Clarke L. 1991. The chromatin structure of centromeres from fission yeast: Differentiation of the central core that correlates with function. J. Cell Biol. 112: 191.

Rea S., Eisenhaber F., O'Carroll D., Strahl B.D., Sun Z.W., Schmid M., Opravil S., Mechtler K., Ponting C.P., Allis C.D., and Jenuwein T. 2000. Regulation of chromatin structure by site-specific histone H3 methyltransferases. Nature 406: 593.

Reinhart B.J. and Bartel D.P. 2002. Small RNAs correspond to centromere heterochromatic repeats. Science 297: 1831.

Reuter G. and Spierer P. 1992. Position effect variegation and chromatin proteins. Bioessays 14: 605.

Richards E.J. and Elgin S.C. 2002. Epigenetic codes for heterochromatin formation and silencing: Rounding up the usual suspects. Cell 108: 489.

Saitoh S., Takahashi K., and Yanagida M. 1997. Mis6, a fission yeast inner centromere protein, acts during G1/S and forms specialized chromatin required for equal segregation. Cell 90: 131.

Schotta G., Ebert A., Dorn R., and Reuter G. 2003. Position-effect variegation and the genetic dissection of chromatin regulation in Drosophila. Semin. Cell Dev. Biol. 14: 67.

Schramke V. and Allshire R. 2003. Hairpin RNAs and retro- 
transposon LTRs effect RNAi and chromatin-based gene silencing. Science 301: 1069.

Shankaranarayana G.D., Motamedi M.R., Moazed D., and Grewal S.I. 2003. Sir2 regulates histone H3 lysine 9 methylation and heterochromatin assembly in fission yeast. Curr. Biol. 13: 1240 .

Steiner N.C. and Clarke L. 1994. A novel epigenetic effect can alter centromere function in fission yeast. Cell 79: 865 .

Steiner N.C., Hahnenberger K.M., and Clarke L. 1993. Centromeres of the fission yeast Schizosaccharomyces pombe are highly variable genetic loci. Mol. Cell. Biol. 13: 4578.

Sullivan B.A., Blower M.D., and Karpen G.H. 2001. Determining centromere identity: Cyclical stories and forking paths. Nat. Rev. Genet. 2: 584.

Takahashi K., Chen E.S., and Yanagida M. 2000. Requirement of Mis6 centromere connector for localizing a CENP-A-like protein in fission yeast. Science 288: 2215.

Takahashi K., Murakami S., Chikashige Y., Funabiki H., Niwa
O., and Yanagida M. 1992. A low copy number central sequence with strict symmetry and unusual chromatin structure in fission yeast centromere. Mol. Biol. Cell 3: 819 .

Verdel A., Jia S., Gerber S., Sugiyama T., Gygi S., Grewal S.I., and Moazed D. 2004. RNAi-mediated targeting of heterochromatin by the RITS complex. Science 303: 672 .

Volpe T.A., Kidner C., Hall I.M., Teng G., Grewal S.I., and Martienssen R.A. 2002. Regulation of heterochromatic silencing and histone H3 lysine-9 methylation by RNAi. Science 297: 1833.

Volpe T., Schramke V., Hamilton G.L., White S.A., Teng G., Martienssen R.A., and Allshire R.C. 2003. RNA interference is required for normal centromere function in fission yeast. Chromosome Res. 11: 137.

Wreggett K.A., Hill F., James P.S., Hutchings A., Butcher G.W., and Singh P.B. 1994. A mammalian homologue of Drosophila heterochromatin protein 1 (HP1) is a component of constitutive heterochromatin. Cytogenet. Cell Genet. 66: 99. 


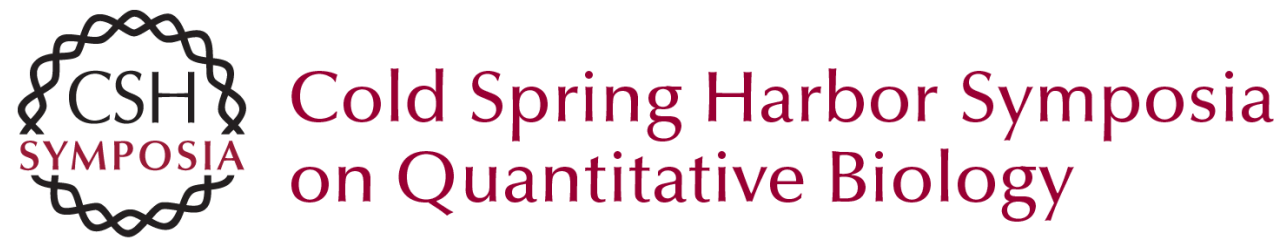

\title{
RNA Interference, Heterochromatin, and Centromere Function
}

\author{
R.C. ALLSHIRE \\ Cold Spring Harb Symp Quant Biol 2004 69: 389-396 \\ Access the most recent version at doi:10.1101/sqb.2004.69.389
}

$\begin{array}{ll}\text { References } & \text { This article cites } 55 \text { articles, } 29 \text { of which can be accessed free at: } \\ \text { http://symposium.cshlp.org/content/69/389.full.html\#ref-list-1 }\end{array}$

License

Email Alerting Receive free email alerts when new articles cite this article - sign up in Service the box at the top right corner of the article or click here. 